\title{
PELATIHAN KETERAMPILAN LAS UNTUK MASYARAKAT USIA PRODUKTIF DI KELURAHAN SUKAJADI KEC. SUKAJADI KOTA PEKANBARU
}

\author{
Sunaryo*, Abrar Ridwan, Legisnal Hakim, Ahmad Kafrawi Nasution, Budi Istana, \\ Lega Putri Utami \\ Teknik mesin, Fakultas Teknik \\ Universitas Muhammadiyah Riau \\ *Email: sunaryo@umri.ac.id
}

\begin{abstract}
Abstrak
Jumlah angkatan kerja di Riau pada Februari 2015 mencapai 2.974.014 orang, atau naik 172,849 orang (6,17 persen) dibandingkan jumlah angkatan kerja pada Februari 2014 sebesar 2.801.165 orang. Jumlah penduduk yang bekerja di Riau pada Februari 2015 sebesar 2,774,245 orang atau bertambah 112,918 orang (4,2 persen) dibandingkan dengan keadaan pada Februari 2014. Tingkat pengangguran terbuka pada Februari 2015 sebesar 6,72 persen, lebih tinggi dibandingkan keadaan pada Februari 2014 (4,99 persen). Sebagian besar para remaja putus sekolah usia produktif tidak memiliki keterampilan berwirausaha sehingga tidak bisa mendapatkan atau menciptakan lapangan kerja. Jumlah bengkel las di kecamatan Sukajadi khususnya kelurahan sukajadi relatif masih kurang dibandingkan dengan jumlah pengguna jasa las. Masih kurangnya pembinaan terhadap Sebagian besar Para remaja putus sekolah usia produktif untuk mendapatkan/menciptakan lapangan pekerjaan khususnya dibidang teknik pengelasan. Teknik mesin fakultas teknik UMRI,menyelenggarakan pengabdian dalam bentuk kegiatan pelatihan keterampilan las pada remaja putus sekolah usia produktif di kelurahan Sukajadi Kecamatan Sukajadi kota Pekanbaru, pelatihan dilaksanakan selama lima hari dengan jumlah peserta 10 orang. Para peserta secara langsung praktek dibawah bimbingan dan pengawasan pelaksana pelatihan yang bertindak sebagai instruktur. Metode demontrasi dan peragaan ini sangat efektif untuk pelatihan las, peserta pelatihan menerapkan modul yang telah didiskusikan dengan tim pelaksana, secara langsung pada peralatan las yang telah disiapkan oleh panitia.
\end{abstract}

Kata kunci: Pengabdian, Angkatan kerja, Pengangguran, Keterampilan las, Wirausaha

\section{PENDAHULUAN}

Jumlah angkatan kerja di Riau pada Februari 2015 mencapai 2.974.014 orang, atau naik 172,849 orang $(6,17$ persen $)$ dibandingkan jumlah angkatan kerja pada Februari 2014 sebesar 2.801.165 orang. Jumlah penduduk yang bekerja di Riau pada Februari 2015 sebesar $2,774,245$ orang atau bertambah 112,918 orang $(4,2$ persen $)$ dibandingkan dengan keadaan pada Februari 2014. Tingkat pengangguran terbuka pada Februari 2015 sebesar 6,72 persen, lebih tinggi dibandingkan keadaan pada Februari 2014 (4,99 persen). Pertanian masih merupakan sektor yang paling dominan dalam penyerapan tenaga kerja di Provinsi Riau. Pada periode Februari 2015, penduduk yang bekerja bekerja di sektor pertanian sebesar 46,09 
persen, meningkat sebesar 3,68 persen dibandingkan dengan kondisi Februari 2014 sebesar 42,41 persen. Penduduk bekerja paling banyak berstatus buruh/karyawan sebesar 44,15 persen sedangkan yang paling keciL adalah penduduk yang bekerja dengan status pekerja bebas di non pertanian, yaitu sebesar 2,79 persen. Jumlah penduduk yang bekerja di bawah jam kerja normal, yaitu yang bekerja kurang dari 35 jam/minggu, pada Februari 2015 sebesar 36,73 persen dari seluruh penduduk yang bekerja. Angka ini lebih tinggi dari keadaan pada bulan Februari 2014 sebesar 34,75 persen. Pada Februari 2015, pekerja pada jenjang pendidikan SD ke bawah masih tetap mendominasi yaitu sebesar 38,48 persen, sedangkan pekerja dengan pendidikan Diploma 2,67 persen dan pekerja dengan pendidikan Sarjana hanya sebesar 8,48 persen.

Pengangguran dan kemiskinan hingga saat ini merupakan masalah besar bangsa Indonesia yang belum bisa terpecahkan. Menurut data BPS Februari 2008, jumlah penganggur terbuka tercatat sebanyak 9,43 juta orang $(8,46 \%)$ per Agustus 2008 serjumlah 9,39 juta orang ( $8,39 \%)$ dari total angkatan kerja sekitar 111,4 juta orang. pengangguran terbuka didominasi lulusan Sekolah Menengah Kejuruan (SMK) besar 17,26 \%, Sekolah menengah Atas (SMA) sebesar 14,31\%, Perguruan Tinggi (PT) 12,59\%, Diploma 11,21 $\%$, lulusan SMP, 9,39 \% dan lulusan Sekolah Dasar (SD) 4,57 \%,dari jumlah penganggur.

Jumlah penganggur tersebut diperkirakan akan bertambah dengan adanya krisis keuangan global sebesar 20 juta orang sehingga dari jumlah penganguran di tahun sebelumnya sebesar 190 juta orang, akan bertambah menjadi 210 juta orang di tahun 2009.

Data terbaru dari Badan Pusat Statistik (BPS) jumlah pengangguran di Riau meningkat. Jumlah pengangguran pada Februari 2015 mencapai $199.769 \quad$ orang. Peningkatan terbesar terjadi pada lulusan Diploma yaitu dari 10,14 persen pada Februari 2014 menjadi 19.49 pada Februari 2015.

Menurut Kepala Bidang Statistik Sosial BPS Provinsi Riau Siti Mardiyah MA peningkatan tersebut seiring dengan bertambahnya jumlah penduduk di Provinsi Riau. Saat ini jumlah penduduk Provinsi Riau sekitar 6.349 juta.

Faktor-faktor yang menyebabkan terjadinya pengangguran di Indonesia, antara lain: Pertama, jumlah pencari kerja lebih besar dari jumlah peluang kerja yang tersedia (kesenjangan antara supply and demand). Kedua, kesenjangan antara kompetensi pencari kerja dengan kompetensi yang dibutuhkan oleh pasar kerja (mis-match), Ketiga, masih adanya anak putus sekolah dan lulus tidak melanjutkan yang tidak terserap dunia kerja/berusaha mandiri karena tidak memiliki keterampilan yang memadai (unskill labour), Keempat, terjadinya pemutusan hubungan kerja (PHK) karena krisis global, dan Kelima, terbatasnya sumber daya alam di kota yang tidak memungkinkan lagi warga masyarakat untuk mengolah sumber daya alam menjadi mata pencaharian. Dari kelima faktor tersebut, faktor pertama, kedua dan ketiga merupakan faktor dominan yang menyebabkan pengangguran di Indonesia. Dari gambaran tersebut di atas maka perlu dikembangkan program-program kewirausahaan 
pemuda dalam rangka mempercepat penurunan angka pengangguran.

Melihat permasalahan diatas, maka Lembaga Penelitian dan Pengabdian Masyarakat Universitas Muhammadiyah Riau (UMRI) melalui Fakultas teknik jurusan teknik mesin telah melakukan kegiatan pengabdian kepada masyarakat. Bentuk kegiatannya adalah:

1. Mengadakan

Pelatihan

Keterampilan pengelasan terhadap generasi muda putus sekolah.

2. Mengadaan pelatihan Kewirausahaan terhadap generasi muda putus sekolah.

Sehubungan dengan pengabdian kepada masyarakat tersebut, dilakukan pendekatan kepada pemuda, Kelurahan Sukajadi kecamatan Sukajadi kota pekanbaru, dan pada akhirnya di sepakati melaksanakan pengabdian kepada masyarakat dari Jurusan teknik Mesin Fakultas Teknik UMRI di kelurahan tersebut dalam bentuk Pelatihan mengelas serta perencanaan pembuatan bengkel terpadu sebagai tempat berwirausaha remaja putus sekolah.

\section{METODE PENGABDIAN}

UMRI sebagai salah satu lembaga pendidikan tinggi, berkewajiban untuk melaksanakan Tri Dharma Perguruan Tinggi yang salah satunya adalah pengabdian kepada masyarakat. Dengan terealisasikan pengabdian kepada masyarakat tersebut diperlukan suatu rencana strategis yang dibarengi dengan skala prioritas.

Mengingat perkembangan kebutuhan dunia pengelasan yang demikian pesat di Riau sementara perbengkelan las masih kurang, maka UMRI Fakultas Teknik yang mempunyai salah satu Program Studi Teknik Mesin memutuskan untuk melakukan pelatihan las kepada remaja kelurahan sukajadi kecamatan sukajadi Kota Pekanbaru.

Untuk Kelancaran kegiatan Fakultas Teknik UMRI bekerjasama dengan Lembaga penelitian dan pengabdian kepada masyarakat UMRI . Dari pelatihan ini diharapakan para peserta mendapatkan pengetahuan dan keterampilan dibidang teknik Pengelasan yang baik . Langkahlangkah pemecahan masalah;

1. Membicarakan jenis pelatihan yang dibutuhkan Para remaja putus sekolah usia produktif

2. Menetapkan waktu pelaksanaan pelatihan

3. Menetapkan lokasi pelaksanaan pelatihan

4. Menyususn modul pelatihan

5. Melengkapi alat dan bahan pelatihan

6. Tim turun kelapangan

7. Pelaksanaan Pelatihan

8. Evaluasi

Sasaran kegiatan pengabdian pada masyarakat ini adalah para remaja putus sekolah usia produktif Kelurahan sukajadi kecamatan sukajadi Kota Pekanbaru. Setiap peserta diharapkan memiliki keterampilan pengelasan yang baik dan dapat hendaknya membuka lapangan pekerjaan sendiri yaitu dengan membuka perbengkelan sendiri.

Dengan demikian program pelatihan ini sangat terkait dengan upaya meningkatkan penanganan pengangguran terhadap para Remaja 
ISSN : 2550-0198

puus sekolah usia produktif. Untuk menghasilkan hasil yang optimal dari kegiatan pelatihan ini, metode yang digunakan adalah :

1. Metode ceramah dan Tanya jawab

Metode ini dipandang perlu untuk menyajikan teori secara umum. Teori yang disampaikan adalah pengenalan alat dan penggunaanya, mesin las, kawat las,dan alat pengaman las lainya.

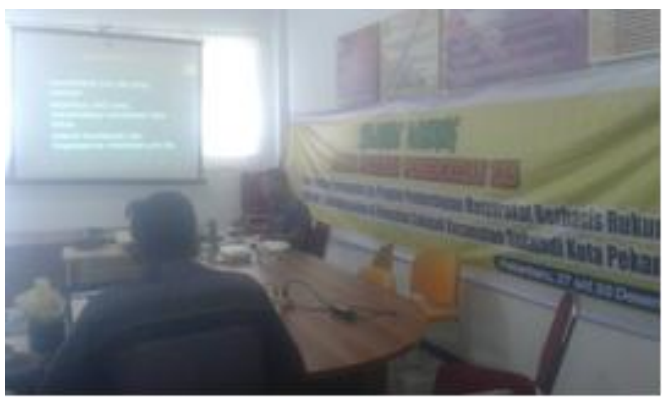

Gambar 1 Penyampaian teori pengelasan

2. Metode demonstrasi

Para instruktur melakukan demonstrasi tentang penggunaan peralatan las serta pengamannya yang terdiri dari :

a. Mesin las

b. Kawat las

c. Alat pengaman ( helem las,sarung tangan dll)

d. Engine catting

e. Mesin bor

f. Gerinda tangan dll

Memperagakan suatu tindakan penggunaan yang dilakukan sesuai dengan Standar Operasional Produk ( SOP)

3. Metode praktikum

Para peserta secara langsung praktek dibawah bimbingan dan pengawasan pelaksana pelatihan yang bertindak sebagai instruktur.
Metode demontrasi dan peragaan ini sangat efektif untuk pelatihan las , peserta pelatihan menerapkan modul yang telah didiskusikan dengan tim pelaksana, secara langsung pada peralatan las yang telah disiapkan oleh panitia.

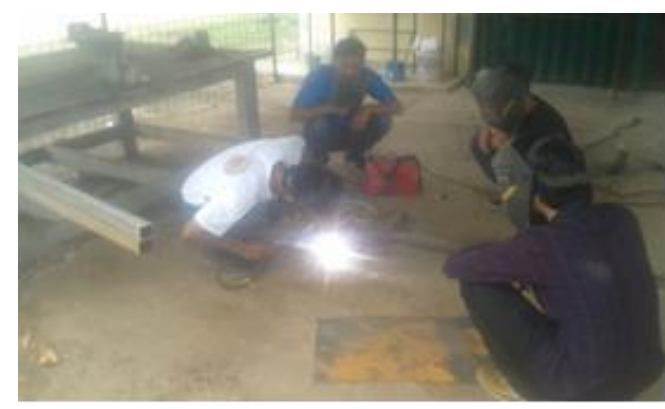

Gambar 2. Pratikum pengelasan

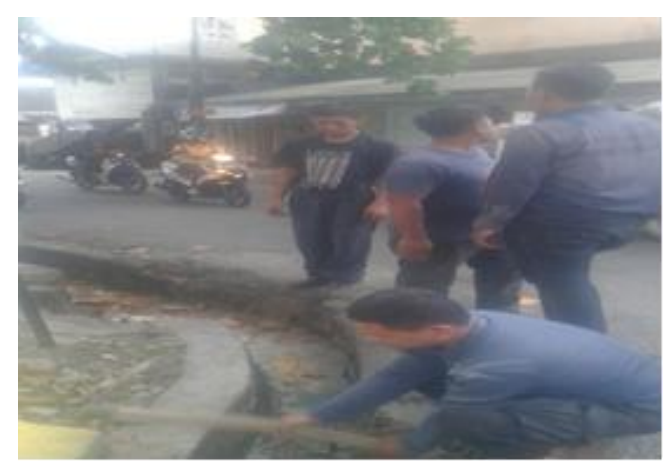

Gambar 3. Proses pemasangan hasil pengelasan

Adapun materi pelatihan disusun sebagai berikut:

Tabel 1. Materi Latihan

\begin{tabular}{lc}
\hline Materi Latihan & $\begin{array}{c}\text { Durasi } \\
\text { (jam) }\end{array}$ \\
\hline Teori pengenalan alat dan & 3 \\
penggunaannya & \\
Keselamatan kerja & 3 \\
Product Knowledge & 4 \\
Las kampuh & 20 \\
Pengelasan produk & 12 \\
Kewirausahaan & 4 \\
\multicolumn{1}{c}{ Jumlah } & $\mathbf{4 6}$ \\
\hline
\end{tabular}

\section{HASIL DAN PEMBAHASAN}

Untuk mengetahui pencapaian tujuan kegiatan dilakukan evaluasi. Bentuk evaluasi yang dilakukan 
adalah mengamati cara kerja peserta mengikuti pelatihan dan dinilai menurut kompetensi keterampilan pengelasan yang baik.

Evaluasi tersebut dilakukan dengan 2 cara yaitu:

1. Pengamatan secara langsung dari instruktur terhadap sikap para peserta, kehadiran peserta dan tanya jawab setiap akan masuk pada topik yang baru.

2. Hasil tes keterampilan pengelasan dari masing-masing peserta .

Indikator keberhasilan dari kegiatan ini adalah:

1. Para peserta memiliki pengetahuan tentang teknik dan cara menggunakan mesin las.

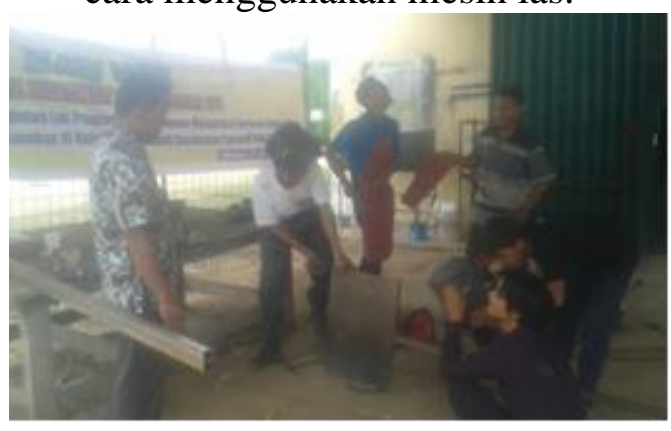

Gambar 4. Praktek pembuatan papan nama kelurahan

2. Para peserta memiliki keterampilan tentang teknik dan cara mengelas yang baik

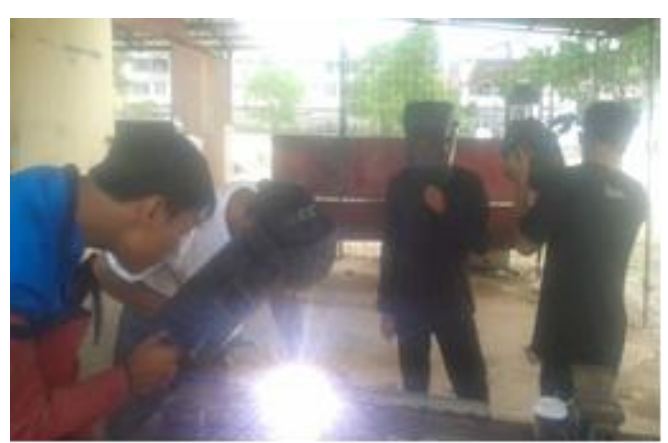

Gambar 5. Praktek proses pengelasan
3. Para peserta memiliki sikap kewirausahaan dan mampu membina kerjasama antar kelompok untuk melakukan usaha perbengkelan las.

Kenyataan ini memberikan gambaran pada kita, bahwa Sebagian besar Para remaja putus sekolah usia produktif ini harus kita berikan bekal keterampilan, agar mereka dapat memasuki lapangan kerja atau membuka lapangan kerja sendiri di masa mendatang untuk itu kami berharap agar pihak terkait dapat membantu baik materil maupun spiritual, terutama Pemerintah kabupaten setempat sebagai pasilisator agar kami dapat melaksanakan kegiatan ini secara rutin setiap semester.

\section{SIMPULAN}

1. Menghasilkan produk berbentuk pintu trali pagar yang di kerjakan langsung oleh peserta pelatihan dengan hasil baik.

2. Sekitar $80 \%$ (8 dari 10 orang peserta) generasi muda telah mengusai sistem pengelasan dengan baik. $20 \%$ yang lain dari peserta pelatihan dalam kondisi cukup menguasai pengelasan tersebut.

3. Sebagian besar Para remaja putus sekolah usia produktif telah memiliki keterampilan untuk mendapatkan atau menciptakan lapangan kerja.

4. Sebagian besar Para remaja putus sekolah usia produktif memiliki keterampilan berwirausaha sehingga bisa mendapatkan atau menciptakan lapangan kerja. 
5. Jumlah bengkel las di kecamatan Sukajadi khususnya kelurahan Sukajadi relatif akan bertambah seiring dengan telah bertambahnya ahli las saat ini.

6. Telah dilaksanakan pembinaan terhadap Sebagian besar Para remaja putus sekolah usia produktif untuk mendapatkan/menciptakan lapangan pekerjaan khususnya dibidang teknik pengelasan.

\section{DAFTAR PUSTAKA}

[1] Dieter, G.E. Engineering design: A materials and processing approach. Tokyo: McGraw-Hill International Book Company. (1983).

[2] Rizal Sani, Las Busur Manual 1, PPPG Teknologi Bandung, 1997

[3] Ramli Soehatman, Sistem Manajemen Keselamatan \& Kesehatan Kerja, Dian Rakyat, Jakarta, 2010.

[4] Strength of Materials. William Nash. Schaum "es Outlines, 1998.

[5] The Lincoln Electric Company, The Procedure Handbook of Arc Welding, The Lincoln Electric Company, 1973

[6] William D. Callister Jr., Material Science and Engineering: An Introduction. John Wiley\&Sons, 2004.

[7] Lembaga Pengabdian Kepada Masyarakat UNP Padang. (2001). Pedoman Kegiatan Pengabdian Kepada Masyarakat. 